\title{
A Survey to Guide the Emerging Role of Allied Health Teams in a Regional Tertiary Hospital Emergency Department
}

\author{
Bede M. Ashley \\ Townsville Hospital and Health Service, bede.ashley@health.qld.gov.au \\ Tilley Pain \\ Townsville Hospital and Health Service, tilley.pain@health.qld.gov.au \\ Heidi Clark \\ Townsville Hospital and health Service, heidi.clark2@health.qld.gov.au \\ Ellen O'Connor \\ Townsville Hospital and Health Service, ellen.oconnor@health.qld.gov.au \\ Liana Schnierer \\ Townsville Hospital and Health Service, Liana.Schnierer@health.qld.gov.au \\ See next page for additional authors
}

Follow this and additional works at: https://nsuworks.nova.edu/ijahsp

Part of the Medicine and Health Sciences Commons

\section{Recommended Citation}

Ashley BM, Pain T, Clark H, O'Connor E, Schnierer L, Laspina K, et al. A Survey to Guide the Emerging Role of Allied Health Teams in a Regional Tertiary Hospital Emergency Department. The Internet Journal of Allied Health Sciences and Practice. 2020 Jan 01;18(2), Article 3.

This Manuscript is brought to you for free and open access by the College of Health Care Sciences at NSUWorks. It has been accepted for inclusion in Internet Journal of Allied Health Sciences and Practice by an authorized editor of NSUWorks. For more information, please contact nsuworks@nova.edu. 


\title{
A Survey to Guide the Emerging Role of Allied Health Teams in a Regional Tertiary Hospital Emergency Department
}

\begin{abstract}
ABSTRACT

Purpose: A multidisciplinary allied health team has worked in The Townsville Hospital Emergency Department for seven years. Patients are referred to the allied health team by medical and nursing staff with the aim of reducing patient admission and improving patient outcomes. However, the type and number of referrals received by the allied health team suggest there is a lack of detailed interdisciplinary knowledge by the referrers. Therefore, the Emergency Department Allied Health Team surveyed other emergency department health professionals to ascertain their knowledge of allied health roles. The results will be used to develop education sessions to fill gaps in knowledge. Methods: A cross-sectional survey consisting of 22 true/false statements and demographic questions was developed by the Emergency Department Allied Health Team. Questions described some of the common triggers for referral to physiotherapy, occupational therapy, social work, and pharmacy staff in the emergency department at the Townsville Hospital. The survey was distributed opportunistically to nursing, medical and physician assistant staff at handover or education sessions. Descriptive statistics were used to describe the data and comparisons used chi squared tests. Results: The response rate for the survey was $63 \%(n=154)$, including 52 doctors (65\%), 95 (59\%) nursing staff, 3 physician assistants (100\%), and 4 who did not state their discipline. Preferred responses were low for questions about occupational therapy's ability to do home visits up to four weeks post emergency department discharge (37.7\%), physiotherapists' necessity to perform mobility assessments $(24.7 \%)$, identifying APINCH acronym as mnemonic for high risk drugs (35.7\%) and the correct application of "close the gap" prescriptions (27.9\%). Staff with more experience and prescribers were more likely to give the preferred response. Conclusions: Some gaps exist in doctors', nurses', and physician assistants' knowledge of the roles of allied health in an emergency department. The knowledge gap decreases as staff experience in emergency departments increases. Therefore, for the allied health team in our emergency department to work at full scope of practice, these knowledge gaps need to be addressed. Our challenge now is to provide sustainable education on the role of allied health in a busy emergency department full of shift working and rotating staff being pulled by a myriad of contrasting priorities.
\end{abstract}

\section{Author Bio(s)}

Bede Michael Ashley, MHlthServMt (Monash University), B Phty (University of Otago). Bede was a senior physiotherapist and part-time team leader in ED and now works as a senior physiotherapist in the Persistent Pain Clinic

Tilley Pain, (PhD), Tilley is a Research Fellow at THHS and an Adjunct Associate Professor at James Cook University. Her role is to build research capacity of allied health professionals within the health service.

Heidi Clark, BSW (James Cook University). Heidi is a Social Worker with several year's experience in the emergency department. This is her first research project.

Ellen O'Connor, B Occ Thy (James Cook University) Ellen is an occupational therapist who worked in the ED on a rotational basis. While in ED, Ellen developed a model of care for home visits for ED patients. She now works in palliative care.

Liana Schnierer, MSW (James Cook University), GCCO (Turning Point), GradDipRehabCouns (University of Tasmania), BA (psych) (University of Tasmania) Liana is a Senior Social Worker and Deputy Director of the Social Work Department. She is currently on maternity leave. 
Kathryn Laspina, B Pharm (James Cook University), BNSc (James Cook University) Kath is a pharmacist with many years of health service experience as a nurse and pharmacist. This is her first research project.

Meghan Esme Fitzpatrick, B Pharm (University Queensland), Postgraduate Certificate Clinical Pharmacy (University Queensland). Meghan is a pharmacist who has worked in the ED for many years and is dedicated to defining the role of pharmacy in ED to assist patients transition to community.

\section{Acknowledgements}

The authors would like to thank the other members of the Emergency Department Allied Health Journal Club and staff and management of The Townsville Hospital Emergency Department

\section{Authors}

Bede M. Ashley, Tilley Pain, Heidi Clark, Ellen O'Connor, Liana Schnierer, Kathryn Laspina, and Meghan E. Fitzpatrick 


\title{
TIJAHSP \\ The Internet Journal of Allied Health Sciences and Practice \\ Dedicated to allied health professional practice and education \\ Vol. 18 No. 2 ISSN 1540-580X
}

\section{A Survey to Guide the Emerging Role of Allied Health Teams in a Regional Tertiary Hospital Emergency Department}

\author{
Bede M. Ashley \\ Tilley Pain \\ Heidi Clark \\ Ellen O'Connor \\ Liana Schnierer \\ Kathryn Laspina \\ Meghan E. Fitzpatrick
}

Townsville Hospital and Health Service

Australia

\begin{abstract}
Purpose: A multidisciplinary allied health team has worked in The Townsville Hospital Emergency Department for seven years. Patients are referred to the allied health team by medical and nursing staff with the aim of reducing patient admission and improving patient outcomes. However, the type and number of referrals received by the allied health team suggest there is a lack of detailed interdisciplinary knowledge by the referrers. Therefore, the Emergency Department Allied Health Team surveyed other emergency department health professionals to ascertain their knowledge of allied health roles. The results will be used to develop education sessions to fill gaps in knowledge. Methods: A cross-sectional survey consisting of 22 true/false statements and demographic questions was developed by the Emergency Department Allied Health Team. Questions described some of the common triggers for referral to physiotherapy, occupational therapy, social work, and pharmacy staff in the emergency department at the Townsville Hospital. The survey was distributed opportunistically to nursing, medical and physician assistant staff at handover or education sessions. Descriptive statistics were used to describe the data and comparisons used chi squared tests. Results: The response rate for the survey was $63 \%$ ( $n=154)$, including 52 doctors (65\%), 95 (59\%) nursing staff, 3 physician assistants (100\%), and 4 who did not state their discipline. Preferred responses were low for questions about occupational therapy's ability to do home visits up to four weeks post emergency department discharge (37.7\%), physiotherapists' necessity to perform mobility assessments (24.7\%), identifying APINCH acronym as mnemonic for high risk drugs (35.7\%) and the correct application of "close the gap" prescriptions $(27.9 \%)$. Staff with more experience and prescribers were more likely to give the preferred response. Conclusions: Some gaps exist in doctors', nurses', and physician assistants' knowledge of the roles of allied health in an emergency department. The knowledge gap decreases as staff experience in emergency departments increases. Therefore, for the allied health team in our emergency department to work at full scope of practice, these knowledge gaps need to be addressed. Our challenge now is to provide sustainable education on the role of allied health in a busy emergency department full of shift working and rotating staff being pulled by a myriad of contrasting priorities.
\end{abstract}

Keywords: cross-sectional studies, emergency service, hospital 


\section{INTRODUCTION}

Allied health professionals have provided ad-hoc health care in emergency departments for decades..$^{1,2}$ Recently, there has been a push to embed multidisciplinary allied health teams in emergency departments in Australia because of growing evidence of their effectiveness. ${ }^{3-5}$ However, the full scope of the roles for allied health professionals in emergency departments are not clearly identified in the literature; as a result, confusion regarding their role still exists and often manifests as inappropriate, or lack of, referrals. ${ }^{6,7}$ Allied health professions common in emergency departments include occupational therapy (OT), physiotherapy (PT), pharmacy, and social work (SW).

The effectiveness of multidisciplinary teamwork is dependent on good communication and knowledge of each other's roles. ${ }^{8}$ The effectiveness is also dependent on individual allied health professions working at full scope of practice within the emergency department team. The allied health team in this study provides regular education sessions for other health professionals in emergency departments with the aim of ensuring appropriate referrals to allied health professionals. Referrals to allied health professionals from emergency departments for incorrect reasons, such as fractured neck of femur or respiratory tract infection, do not reduce length of stay for admitted older patients. ${ }^{9}$ However, it has been noted that primary contact PTs do reduce waiting and treatment times for people with musculoskeletal conditions. ${ }^{5}$

There are numerous indications emergency department health professionals who refer to the emergency department allied health team do not have a complete understanding of allied health roles. For example, prior to working with PTs, many physicians did not have a complete understanding of the full scope of PT practice..$^{10} \mathrm{~A}$ survey conducted on 117 doctors, nurses, and social workers in 20 medical emergency rooms in the New York City area found differences in how SW and other health professionals viewed the emergency room SW role. ${ }^{11}$ The contributions of social workers to medical emergency rooms is not always clear to the wider emergency department health care team. ${ }^{12}$ Another study showed emergency department physicians had difficulty articulating the OT role within their inter-professional team. ${ }^{13}$ Furthermore, there was no set pattern of referral to OT services, suggesting variations in the understanding and utilisation of the role. ${ }^{14,15}$ Some of these examples of knowledge gaps were apparent in our emergency department too.

This study was conducted as a research capacity building initiative (RCBI) for Emergency Department Allied Health Journal Club members. All Journal Club members were novice researchers supported by an experienced researcher to identify the research question, design methods to appropriately address the question and then perform the study. JC members were trained in complying with the ethics process, designing questionnaires and collecting and analysing data.

This survey aimed to measure knowledge level of the health team at the Townsville Hospital Emergency Department. The results of this survey will be used to refine education on the roles of allied health professionals in emergency departments to maximise patient referrals for allied health interventions that optimise patient journey and outcomes. The updated education will be used to counteract incomplete or inappropriate referrals to allied health team members. An additional aim of this research was to build the research capacity of the allied health team within the emergency department.

\section{METHODS}

\section{Survey Development}

A cross sectional survey was developed by the emergency department allied health team with assistance from a research fellow using a published method. ${ }^{16}$ Potential questions were proposed by current emergency department allied health professionals to reflect their core roles/processes that seemed poorly understood by other emergency department health professionals. An initial pool of approximately 70 questions was iteratively discussed by team members for relevance and applicability to the local emergency department context. The final number of questions was reduced to fit on a single page hardcopy survey, thereby including only questions with potential impact on referral patterns within the emergency department to maximise current allied health team members' roles. The draft survey was critiqued and reworked within team meetings and then trialled on health professionals external to the emergency department. Adjustments continued until consensus was reached on the final survey consisting of 22 questions on the roles of allied health professionals and two or three demographic questions for doctors and nurses respectively. The categorical responses "yes," "no," and "don't know" were used for all questions pertaining to allied health roles. The questions were phrased to elicit some negative and some positive responses to challenge the respondents to answer each question independently.

The questionnaires were distributed over two weeks in 2015 to nursing staff at morning and afternoon handover meetings, and to doctors and physician assistants at their weekly education sessions. The surveys were distributed and collected within the same session to maximise return rates. As the project was deemed a Quality Improvement Activity, an endorsement of non-research 
was obtained from the Townsville Hospital and Health Service (THHS) Human Research Ethics Committee (HREC) prior to commencement of the project (HREC/15/QTHS/128).

\section{Data Collection}

The survey was anonymous with minimal demographic data collected. Demographic data collected included job role and level (staff specialist, registrar, senior house officer, junior house officer, intern, physician assistant, nurse unit manager, clinical nurse coordinator, nurse educator, clinical nurse, registered nurse, enrolled nurse, nurse practitioner), and length of time worked in THHS ED (< 1 year, 1-4 years, 5+ years). Nurses were asked whether they worked primarily in the Emergency Department or the Short Stay Unit (adjacent to ED).

\section{Data Analysis}

The data was manually entered directly into Statistical Package for Social Sciences (SPSS) version 22 (IBM Corp, USA) for analysis. Results were aggregated for individual questions and presented as proportions in tabular form. Comparisons were made across disciplines and years of experience using Chi Square tests as all data was categorical. Comparisons were considered significant if the $p$ value was $<0.05$.

\section{RESULTS}

The response rate for the survey was $63 \%(n=154)$ of 244 staff working in the emergency department at the time. Respondents included 52 doctors (65\%), $95(59 \%)$ nursing staff, 3 physician assistants (100\%), and 4 who did not state their discipline. Surveys were included in the analysis if $80 \%$ or more fields had been completed.

Table 1. Time Worked in the Emergency Department (ED) by Prescriber/non-prescriber.

\begin{tabular}{|l|l|l|l|}
\hline Time worked in ED & Number of Doctors (\%) & Number of Nurses (\%) & Total Numbers (\%) \\
\hline Less than a year & $26(51 \%)$ & $23(24 \%)$ & $49(35 \%)$ \\
\hline One to four years & $15(29 \%)$ & $33(35 \%)$ & $48(32 \%)$ \\
\hline Five or more years & $10(20 \%)$ & $39(41 \%)$ & $49(33 \%)$ \\
\hline
\end{tabular}

\section{Time Worked in Emergency Department}

The time worked in the emergency department displayed an inverse relationship between medical and nursing staff (Table 1). Overall, $35 \%$ of responders had worked in the emergency department less than a year ( $51 \%$ of doctors, $24 \%$ of nurses), $32 \%$ had worked between one and four years (29\% doctors, $35 \%$ nurses), and $33 \%$ had worked five years or longer $(20 \%$ doctors, $41 \%$ nurses). Ten questions were significantly different when comparing the preferred answer to the length of time respondents have worked in emergency department. In most cases, respondents who had worked the longest gave the preferred response (Table 2).

Table 2. Questions with a Significant Difference by Time Worked in the Emergency Department (ED)

\begin{tabular}{|l|l|l|l|l|l|}
\hline Question & $\begin{array}{l}\text { Preferred } \\
\text { answer }\end{array}$ & $<$ year & $1-4$ years & $>$ 4years & P-value \\
\hline I refer patients with fractured ribs to ED physiotherapy & True & $46.1 \%$ & 36.2 & 68.8 & 0.007 \\
\hline $\begin{array}{l}\text { I refer to either ED physiotherapy or ED occupational } \\
\text { therapy when a patient presents with a burn that } \\
\text { crosses a joint }\end{array}$ & True & 65.4 & 91.7 & 90.0 & $<0.001$ \\
\hline $\begin{array}{l}\text { I can refer patients with acute hand injuries to the ED } \\
\text { occupational therapists }\end{array}$ & True & 63.5 & 85.4 & 90.0 & 0.001 \\
\hline $\begin{array}{l}\text { I can only issue pre-labelled medications (Emergency } \\
\text { Packs/EP's) in the absence of an ED pharmacist. }\end{array}$ & True & 42.3 & 41.7 & 77.6 & $<0.001$ \\
\hline $\begin{array}{l}\text { I am aware that there is an allied health/CHIP after- } \\
\text { hours referral book }\end{array}$ & True & 54.3 & 84.8 & 87.5 & .001 \\
\hline $\begin{array}{l}\text { I can request the ED pharmacist to dispense Close the } \\
\text { Gap prescriptions }\end{array}$ & False & 21.2 & 35.4 & 27.1 & .020 \\
\hline
\end{tabular}




\begin{tabular}{|l|l|l|l|l|l|}
\hline $\begin{array}{l}\text { I refer patients requiring changes to a Dose } \\
\text { Administration Aid to the ED pharmacist prior to } \\
\text { discharge }\end{array}$ & True & 45.1 & 62.5 & 70.8 & .020 \\
\hline $\begin{array}{l}\text { I can refer patients in the waiting room to the ED social } \\
\text { workers before they are allocated a treating clinician }\end{array}$ & True & 30.8 & 68.1 & 83.3 & $<0.001$ \\
\hline $\begin{array}{l}\text { I am aware the CHIP Nursing role is based within the } \\
\text { allied health ED team (CHIP previously EAC) }\end{array}$ & True & 55.8 & 68.8 & 77.6 & 0.034 \\
\hline $\begin{array}{l}\text { I can refer to the ED occupational therapist to assess a } \\
\text { patients' cognitive function }\end{array}$ & True & 52.0 & 68.8 & 75.5 & 0.031 \\
\hline
\end{tabular}

\section{Professional Comparisons}

We grouped professions into one of two groups: Prescribers (doctors, nurse practitioners, physician assistants) who have diagnostic and ordering capabilities as part of their role, and Non-Prescribers (clinical nurse consultants, registered nurses, enrolled nurses). There was a significant difference in 6 questions (Table 3). Prescribers gave the preferred answer more often than nonprescribers. An exception was the lower preferred response rate to the question pertaining to the acronym APINCH (Antimicrobials, Potassium, Insulin, Narcotics, Chemotherapeutic agents, Heparin and other anticoagulants) by prescribers.

Table 3. Questions with a Significant Difference Between Prescribers and Non-Prescribers

\begin{tabular}{|l|l|l|l|l|}
\hline Question & $\begin{array}{l}\text { Preferred } \\
\text { answer }\end{array}$ & Prescribers & $\begin{array}{l}\text { Non- } \\
\text { prescribers }\end{array}$ & P value \\
\hline $\begin{array}{l}\text { I can request the ED pharmacist to dispense Close the Gap } \\
\text { prescriptions }\end{array}$ & False & $41.4 \%$ & $20.0 \%$ & 0.012 \\
\hline $\begin{array}{l}\text { My awareness of the acronym APINCH has been increased } \\
\text { through ED pharmacy education }\end{array}$ & True & 18.6 & 47.0 & $<0.001$ \\
\hline I refer all cases of domestic violence to ED social work & True & 80.1 & 62.1 & 0.045 \\
\hline $\begin{array}{l}\text { I can refer to the ED occupational therapist to assess a } \\
\text { patients' cognitive function }\end{array}$ & True & $78.0 \%$ & $55.8 \%$ & 0.002 \\
\hline $\begin{array}{l}\text { I refer all patients needing mobility assessments to the } \\
\text { physiotherapist }\end{array}$ & False & $41.4 \%$ & $15 \%$ & 0.002 \\
\hline $\begin{array}{l}\text { I can refer to ED physiotherapists to prescribe exercises to } \\
\text { treat patients with peripheral vertigo }\end{array}$ & True & $79.7 \%$ & $40.0 \%$ & $<0.001$ \\
\hline
\end{tabular}

\section{Allied Health Emergency Department Team}

Most respondents gave the preferred answer to most of the general emergency department allied health team questions. However, less than half ( $48 \%$ ) gave the preferred answer to the question regarding patients able to be referred to any emergency department allied health team member for discharge planning (Table 4).

Table 4. Results by Question for All Participants

\begin{tabular}{|l|l|l|l|l|l|}
\hline Question from the survey & $\begin{array}{l}\text { Preferred } \\
\text { answer }\end{array}$ & True & False & $\begin{array}{l}\text { Don't } \\
\text { know }\end{array}$ & $\begin{array}{l}\text { Not } \\
\text { stated }\end{array}$ \\
\hline $\begin{array}{l}\text { I am aware that the same allied health team provides services to both } \\
\text { the ED and Short Stay Unit }\end{array}$ & True & 90.9 & 1.3 & 7.8 & 0.0 \\
\hline $\begin{array}{l}\text { I am aware the CHIP Nursing role is based within the allied health ED } \\
\text { team }\end{array}$ & True & 66.9 & 4.5 & 28.6 & 0.0 \\
\hline $\begin{array}{l}\text { I can refer patients for discharge planning to any ED allied health } \\
\text { team member }\end{array}$ & True & 48.1 & 20.1 & 28.6 & 3.2 \\
\hline $\begin{array}{l}\text { I am aware that there is an allied health/CHIP after-hours referral } \\
\text { book }\end{array}$ & True & 71.4 & 5.2 & 17.5 & 5.8 \\
\hline
\end{tabular}




\begin{tabular}{|c|c|c|c|c|c|}
\hline $\begin{array}{l}\text { I can refer patients with acute hand injuries to the ED occupational } \\
\text { therapist }\end{array}$ & True & 77.9 & 3.2 & 18.2 & 0.6 \\
\hline $\begin{array}{l}\text { I can refer to the ED occupational therapist to assess a patient's } \\
\text { cognitive function }\end{array}$ & True & 64.3 & 7.8 & 27.9 & 0.0 \\
\hline $\begin{array}{l}\text { I am aware the ED occupational therapist can follow up patients at } \\
\text { high risk of representations for up to four weeks post discharge from } \\
\text { ED }\end{array}$ & True & 37.7 & 11.0 & 50.0 & 1.3 \\
\hline $\begin{array}{l}\text { I can refer to either ED physiotherapy or ED occupational therapy } \\
\text { when a patient presents with a burn that crosses a joint }\end{array}$ & True & 81 & 6.5 & 11.0 & 0.6 \\
\hline $\begin{array}{l}\text { I refer all patients needing mobility assessments to the } \\
\text { physiotherapists }\end{array}$ & False & 70.8 & 24.7 & 1.9 & 2.6 \\
\hline $\begin{array}{l}\text { I can refer physiotherapists to prescribe exercises to treat patients } \\
\text { with peripheral vertigo }\end{array}$ & True & 55.2 & 7.8 & 37.0 & 0.0 \\
\hline $\begin{array}{l}\text { I refer all patients who require crutches to be reviewed by an ED } \\
\text { physiotherapist }\end{array}$ & False & 23.4 & 67.5 & 7.8 & 1.3 \\
\hline I refer patients with fractured ribs to ED physiotherapy & True & 49.4 & 32.5 & 16.2 & 1.9 \\
\hline $\begin{array}{l}\text { I can refer patients with hand injuries to an ED physiotherapist to } \\
\text { make simple thermoplastic splints }\end{array}$ & True & 53.9 & 8.4 & 37.0 & 0.6 \\
\hline $\begin{array}{l}\text { I can only issue pre-labelled medications (Emergency Packs - EPs) in } \\
\text { the absence of ED pharmacist }\end{array}$ & True & 53.2 & 27.9 & 18.8 & 0.0 \\
\hline $\begin{array}{l}\text { I am aware that ED pharmacists recommend that a patient's "own } \\
\text { medications" remain with them in hospital at all times }\end{array}$ & True & 77.3 & 9.7 & 12.3 & 0.6 \\
\hline $\begin{array}{l}\text { My awareness of the acronym APINCH has been increased through } \\
\text { ED pharmacy education }\end{array}$ & True & 35.7 & 26.6 & 36.4 & 1.3 \\
\hline $\begin{array}{l}\text { I can request the ED pharmacist to dispense Close the Gap } \\
\text { prescriptions }\end{array}$ & False & 25.3 & 27.9 & 46.1 & 0.6 \\
\hline $\begin{array}{l}\text { I refer patients requiring changes to a Dose Administration Aid to the } \\
\text { ED pharmacist prior to discharge }\end{array}$ & True & 58.4 & 5.8 & 33.8 & 1.9 \\
\hline I refer all patients on the sexual assault pathway to ED SW & True & 71.4 & 11.7 & 15.6 & 1.3 \\
\hline I refer all cases of domestic violence to ED social work & True & 68.2 & 22.1 & 8.4 & 1.3 \\
\hline $\begin{array}{l}\text { I refer distressed families to ED social work for support while patients } \\
\text { are undergoing treatment }\end{array}$ & True & 95.5 & 3.2 & 0.6 & 0.6 \\
\hline $\begin{array}{l}\text { I can refer patients in the waiting room to the ED social workers } \\
\text { before they are allocated a treating clinician }\end{array}$ & True & 59.1 & 9.7 & 29.9 & 1.3 \\
\hline
\end{tabular}

\section{Occupational Therapy}

Most respondents provided the preferred answer to questions about OT's involvement with hand therapy, burns, and cognitive assessments (Table 4). However, $37.7 \%$ gave the preferred response to OT's ability to do home visits up to four weeks post emergency department discharge.

\section{Physiotherapy}

The proportion of preferred responses to PT questions varied substantially (Table 4). A low proportion of preferred responses was given for the question about mobility assessments (24.7\%). Approximately half gave preferred responses for questions about fractured ribs $(49.4 \%)$ and referring to PT for vertigo $(55.2 \%)$ and hand injuries $(53.9 \%)$.

\section{Pharmacy}

A high proportion of respondents gave the preferred answer to questions pertaining to pre-labelled medications (53.2\%), patients' own medications (77.3\%), and dose administration aids (58.4\%) (Table 4). Less than half the respondents gave the preferred response to questions about the APINCH acronym (35.7\%) and close the gap prescriptions (27.9\%). 


\section{Social Work}

A moderate to high proportion of respondents gave the preferred answer to all questions (Table 4). The lowest proportion was for referring patients to SW while still in the waiting room (59.1\%) and the highest proportion was for the question pertaining to social workers supporting distressed families (95.5\%).

\section{DISCUSSION}

This survey measured emergency department health professionals' knowledge of allied health roles within the emergency department. The rationale for conducting the survey was two-fold. First, it was to measure emergency department health professionals understanding of allied health roles. Second, it was to refine how individual allied health roles deliver education within emergency department to optimise the allied health role within the multidisciplinary team to improve patient outcomes, meet National Emergency Access Targets (NEAT), and reduce representations. An unexpected outcome was the assistance it provided with reviewing policies and procedures that impacted on allied health referrals.

The $63 \%$ response rate is a good representation of ED staff and their knowledge at the time of the survey. The high proportion of junior doctors compared to senior doctors is typical of tertiary teaching hospitals due to the high turnover/rotation of interns and registrars. More senior staff and prescribers tended to provide preferred responses more frequently than junior staff and nonprescribers.

\section{Occupational Therapy}

The high proportion of preferred responses about the OT role suggest their role is relatively well known in our emergency department. This was a positive finding considering the team can relate to the emergency department experience in Sweden where OTs have difficulty explaining their role and feel they must justify their approaches. ${ }^{17}$

One exception to the high preferred response rate is the ability for OTs to conduct home visits up to four weeks post discharge. OT have provided home visit services for several years recognised as part of complex interventions to reduce readmission and falls in elderly patients. ${ }^{18,19}$ Regular education sessions on "what occurs on an OT home visit" had been conducted in our emergency department. However, referral rates for home visit were low. Therefore, the emergency department's OT used the opportunity to transition from a rapid assessment and referral to an intervention-based service. Early analysis suggests increased post-discharge follow up reduces emergency department representations for high risk patient groups by approximately $40 \%$ since the introduction of the home visits (unpublished data). This OT model of care is the subject of future study to explore the reduction in representations.

\section{Physiotherapy}

Responses for the peripheral vertigo question had a low preferred response rate (55\%). A lack of awareness of peripheral vertigo has been noted among doctors and patients. (20) Benign paroxysmal positional vertigo (BPPV) is a common and easily treatable condition using repositioning techniques often performed by PT. ${ }^{21}$ Previously, BPPV was infrequently referred to PT in our emergency department. Following education, all vertigo is now referred to PT in our ED, triggering a need to educate on the difference between BPPV and other vertigos.

Responses for referrals to PT for fractured ribs was also low (49\%). Presentations for fractured ribs are common in emergency departments, and PT plays an integral role in reducing the development of complications associated with blunt chest trauma. ${ }^{22,23}$ Early input by PT may play a role in preventing unplanned representations due to pneumonia and respiratory failure. ${ }^{24} \mathrm{~A}$ low preferred response rate $(24.7 \%)$ to the question regarding referring all mobility assessments to PT may be misleading. Physiotherapists are often regarded as the mobility experts; however, completing mobility assessments are within the scope for all clinical staff.

\section{Pharmacy}

Over the last decade, emergency department pharmacy services have become an integral and well accepted addition to the traditional emergency department professions. ${ }^{25}$ Pharmacy led education to TTH ED medical and nursing streams is routine. Despite this, the preferred response rate for four of the five pharmacy survey questions was under $60 \%$.

Continuity of care between hospital and community is a core role for emergency department pharmacists. Questions relating to this theme displaying a low preferred response rates include Close the Gap prescription limitations, emergency pack provision, and application of Dose Administration Aids. Incomplete knowledge of these continuity of care tools may result in delays or failure of patients to transition back to community safely. 
The lowest preferred response rate was recorded for the APINCH question (35.7\%). The APINCH acronym (Antimicrobials Potassium - Insulin - Narcotics - Chemotherapeutic agents - Heparin and other anticoagulants) is widely used internationally and describes groups of high-risk medications with potential for serious adverse events. ${ }^{26}$ This question was phrased to measure the effectiveness of pharmacy education rather than health professionals' level of knowledge. APINCH had been the subject of fortnightly education to emergency department nursing staff, and to a lesser extent, medical staff (at orientation for interns, quarterly for resident medical officers) in the lead up to the survey period. The disparity in responses may reflect the frequency of education to nursing versus medical staff.

\section{Social Work}

Referring distressed families to SW fits the stereotype of their role which recorded the highest preferred response rate. ${ }^{27,28}$ However another explanation may include the effectiveness of the intense education and change in process by SW in emergency department. The education provided regularly was regarding the Trauma Response Pathway which allows families into the Resus room for support through the grieving process.

Responses for the sexual assault question had a high response rate $(71 \%)$. The department policy and procedures now state $100 \%$ of sexual assault presentations are to be referred to SW. This policy was introduced because lack of SW intervention in sexual assault may result in traumatisation and some options not being presented to the patient in a timely manner (including forensic examination), thereby risking insufficient evidence collection. In 2016, the sexual assault pathway was changed using an external agency, the Sexual Assault Support Service (SASS), and there was a move towards creating the first Sexual Assault Response Team (SART), trauma-informed model of care, to be implemented in emergency departments in Queensland. Social work education now focusses on referrals to the SART team. Equally concerning was the low preferred responses to domestic violence referrals. The emergency department SW team had been providing intensive education for automatic referral to SW when Domestic Violence identified in line with Recommendation 59 of Queensland Taskforce on Domestic and Family Violence which states: The Taskforce recommends that the Queensland Government and DVConnect work in partnership to develop a model to provide immediate access to specialist domestic and family support and referral services within public and private maternity hospitals and emergency departments..$^{29}$

The preferred response to the question regarding referral of patients in the waiting room was $59.1 \%$. At the time of the survey, this pathway was still being developed in the emergency department and may account for the lowest proportion of preferred responses for SW. The pathway was introduced to ensure rapid access to patients and their families in times of high distress. The evidence suggests a low admission rate of patients reviewed by SW in emergency department waiting rooms. ${ }^{12}$ Potential benefits of being seen in the waiting room could be that patients receive a quicker and more appropriate service and acute beds are not filled by non-medical emergencies.

\section{Limitations}

Some limitations to our study are inherent in survey research. First, limiting the number of questions to fit on a single page means only a snapshot of potential questions can be included. However, we kept it short because our intention was to increase response rate and measure knowledge of core roles. Second, clarification of some terminology was a recommendation from trialling the survey. However, not all terminology was changed as it was that knowledge we wished to measure. Third, this survey was conducted in one site and so cannot be generalised. Nevertheless, the process of using a survey to identify knowledge gaps and opportunities for allied health roles in emergency departments can be generalized to all emergency departments. Fourth, limitations of all survey design mean there is likely to be a response bias from more experienced staff or those with strong professional relationships to the allied health staff distributing the surveys. Fifth, how staff respond in a survey may not be a true reflection of how they act in their clinical practice.

\section{CONCLUSION}

We have been able to quantify that some gaps exist in doctors' and nurses' knowledge of the roles of allied health professionals in emergency departments. We have also found that this gap decreases as staff experience in an emergency department increases. Therefore, if allied health teams in emergency departments are to realise their full service potential, these gaps need to be addressed. Overall, this study highlights the difficulty of sustaining collective knowledge in an ED environment. Our challenge now is to provide sustainable education in a busy department full of shift working and rotating staff, being pulled by a myriad of contrasting priorities. 


\section{$\underline{\text { References }}$}

1. Farber JM. Emergency Department Social Work. Social Work in Health Care. 1978;4(1):7-18.

2. Cohen V, Jellinek SP, Hatch A, Motov S. Effect of clinical pharmacists on care in the emergency department: a systematic review. Am J Health Syst Pharm. 2009;66(15):1353-61.

3. Crock C. Patient and Family Centred Care in Australia. [Submission to the National Health and Hospital Reform Commission]. In press 2008.

4. Moss JE, Houghton LM, Flower CL, Moss DL, Nielsen DA, Taylor DM. A multidisciplinary care coordination team improves emergency department discharge planning practice. The Medical Journal of Australia. 2002;177(8):435-9.

5. Bird S, Thompson C, Williams KE. Primary contact physiotherapy services reduce waiting and treatment times for patients presenting with musculoskeletal conditions in Australian emergency departments: an observational study. Journal of Physiotherapy. 2016;62(4):209-14.

6. Kilner $E$. What evidence is there that a physiotherapy service in the emergency department improves health outcomes? A systematic review. J Health Serv Res Policy. 2011;16(1):51-8.

7. Arendts G, Fitzhardinge S, Pronk K, Donaldson M, Hutton M, Nagree Y. The impact of early emergency department allied health intervention on admission rates in older people: a non-randomized clinical study. BMC Geriatrics. 2012;12(1):8.

8. Creswick N, Westbrook JI, Braithwaite J. Understanding communication networks in the emergency department. BMC Health Services Research. 2009;9(1):247.

9. Arendts G, Fitzhardinge S, Pronk K, Hutton M. Front-loading allied health intervention in the emergency department does not reduce length of stay for admitted older patients. International Journal of Clinical Practice. 2013;67(8):807-10.

10. Lebec MT, Cernohous S, Tenbarge L, Gest C, Severson K, Howard S. Emergency department physical therapist service: a pilot study examining physician perceptions. Internet Journal of Allied health Sciences and Practice. 2010;8(1):8.

11. Garces Carranza CM. The social worker in the emergency room: ProQuest Dissertations \& Theses; 2002.

12. Auerbach C, Mason SE. The value of the presence of social work in emergency departments. Soc Work Health Care. 2010;49(4):314-26.

13. Bissett M, editor Occupational therapy in the emergency department: perceptions of medical staff. Australian Occupational Therapy Journal Vol 58, S1: Occupational Therapy Australia, 24th National Conference and Exhibition, 29 June-1 July 2011, Gold Coast Convention Centre; 2011.

14. Cusick A, Johnson L, Bissett M. Occupational therapy in emergency departments: Australian practice. J Eval Clin Pract. 2009;15(2):257-65.

15. Carlill G, Gash E, Hawkins G. Preventing unnecessary hospital admissions: an occupational therapy and social work service in an accident and emergency department. British Journal of Occupational Therapy. 2002;65(10):440-5.

16. Streiner D, Norman G, Cairney J. Health measurement scales: a practical guide to their development and use. Fifth ed. Oxford: Oxford University Press; 2015.

17. Spang L, Holmqvist K. Occupational therapy practice in emergency care: Occupational therapists' perspectives. Scandinavian Journal of Occupational Therapy. 2015;22(5):345-54.

18. Nielsen LM, Maribo T, Kirkegaard H, Petersen KS, Oestergaard LG. Development of a complex intervention aimed at reducing the risk of readmission of elderly patients discharged from the emergency department using the intervention mapping protocol. BMC Health Serv Res. 2018;18(1):588.

19. Chu MM, Fong KN, Lit AC, Rainer TH, Cheng SW, Au FL, et al. An occupational therapy fall reduction home visit program for community-dwelling older adults in Hong Kong after an emergency department visit for a fall. J Am Geriatr Soc. 2017;65(2):364-72.

20. Arshad M, Abbas S, Qureshi IA. Delay in diagnosis and treatment of benign paroxysmal positional vertigo in current practice. Journal of Ayub Medical College Abbottabad. 2013;25(1-2):93-5.

21. Plummer L, Sridhar S, Beninato M, Parlman K. Physical therapist practice in the emergency department observation unit: descriptive study. Physical Therapy. 2015;95(2):249-56.

22. Unsworth A, Curtis K, Asha SE. Treatments for blunt chest trauma and their impact on patient outcomes and health service delivery. Scand J Trauma Resusc Emerg Med. 2015;23:17.

23. Sharma OP, Oswanski MF, Jolly S, Lauer SK, Dressel R, Stombaugh HA. Perils of rib fractures. The American Surgeon. 2008;74(4):310-4.

24. van Vledder M, Hagenaars T, Verhofstad M. The elderly patient with multiple rib fractures. Dutch Journal of Medicine. 2015;2015(159):1-5.

25. Fairbanks RJ, Hays DP, Webster DF, Spillane LL. Clinical pharmacy services in an emergency department. American Journal of Health-System Pharmacy. 2004;61(9):934-7.

26. Roughead L, Semple S, Rosenfeld E. Literature review: medication safety in Australia. Australian Commission on Safety and Quality in Health Care. 2013. 
27. Lewis B, McNabb W, Rallied healthmas S. The role of the social worker in the accident and emergency department of a district general hospital. Emergency Medicine Journal. 1994;11(1):21-4.

28. Moore M, Ekman E, Shumway M. Understanding the critical role of social work in safety net medical settings: framework for research and practice in the emergency department. Soc Work Health Care. 2012;51(2):140-8.

29. Heinemann AW. State-of-science symposium on postacute rehabilitation: setting a research agenda and developing an evidence base for practice and public policy - Executive summary. American Journal of Speech - Language Pathology. 2007;16(4):290-4. 